\title{
Workplace Exposures
}

\author{
Janet T. Lee, MD, MS, FACS, FASCRS ${ }^{1}$ Wolfgang B. Gaertner, MD, MSc, FACS, FASCRS ${ }^{1}$ \\ ${ }^{1}$ Division of Colon and Rectal Surgery, Department of Surgery, \\ University of Minnesota, Minneapolis, Minnesota \\ Address for correspondence Wolfgang B. Gaertner, MD, MSc, FACS, \\ FASCRS, Division of Colon and Rectal Surgery, Department of Surgery, \\ University of Minnesota, 420 Delaware St SE, MMC 450, Minneapolis, \\ Clin Colon Rectal Surg 2019;32:435-441. \\ MN 55455 (e-mail: gaert015@umn.edu).
}
Abstract
Keywords
- workplace exposure
- needlestick injury
- infectious risk
- system-based practice
- colon and rectal surgery

Workplace exposure in colorectal surgery is unique compared with other surgical specialties and generally underreported. Although the most common device-associated exposure in surgery is suture needle injury, colorectal surgeons are increasingly exposed to gastrointestinal-related infectious agents, radiation, and other hazards in multiple different clinical settings. Highlighting the unique workplace exposures in colorectal surgery may help increase awareness, improve education, and identify possible targets for early intervention in order to minimize these risks.
In colorectal surgery, the potential for workplace exposures is present in every aspect of patient care. Colorectal surgeons are at risk of not only blood or body fluid (BBF) exposures and sharps injuries in the operating room and during endoscopy but also radiation exposure during pelvic floor and fecal incontinence procedures. The aim of this study is to review and highlight the incidence and risks of BBF exposures, treatment of exposures, and ways to minimize risk.

\section{Blood and Body Fluid Exposure}

\section{Sharps Injuries}

Injury to medical personnel from sharp instruments or needles is high, with an estimated 385,000 injuries among health care workers per year. ${ }^{1}$ This rate is likely much higher due to underreporting. As many as $50 \%$ of sharps injuries are unreported, according to the Occupational Safety and Health Administration (OSHA). Of the sharps injuries that occur each year in the United States, most studies have shown that 38 to $66 \%$ occur during surgery. ${ }^{2}$ The exact incidence in colorectal surgery is unknown, however.

Myers et $\mathrm{al}^{3}$ investigated sharps injuries in the operating room at a large academic institution, determining risk factors for injury and incidence rates. This study included data from 2001 to 2010 comprising 333,073 surgical cases. During the study period, 2,113 exposure events were reported, with the majority (86.4\%) occurring during elective procedures. The overall rate of exposure was 6.3 per 1,000 procedures or 2.9 per 1,000 procedure hours. Orthopaedic surgery had the highest proportion of exposures (21.1\%) followed by general surgery (18.2\%). Cardiac surgery, however, had the highest exposure rate per 1,000 procedures (15.3\%), and obstetrics/gynecology had the highest exposure rate per 1,000 procedure hours. The exposure rate for general surgery procedures was 6.7 per 1000 procedures and 2.9 per 1,000 procedure hours. The most common device associated with exposure was a suture needle, involving $49 \%$ of exposures. Other sharps and unknown devices were responsible for $12.6 \%$ and $11.4 \%$ of exposures, respectively. Of those who had a sharps injury in this study, the highest percentages were in fellows, residents, and students (40\%) followed by attending physicians (27.4\%). Significant risk factors for sharps injuries in this study were procedure duration more than 6 hours, estimated blood loss $>500 \mathrm{~mL}$, and number of personnel working in the surgical field.

Several other studies have looked at sharps injuries within a surgical department. A recent study evaluated the prevalence of sharps injuries, attitude changes, and prevention practices in an urban academic hospital surgery department. ${ }^{4}$ A survey was administered to fellows, residents, medical students, medical assistants, and nurses, with a $24.8 \%$ response rate. Of the respondents, $38.7 \%$ reported sharps injuries. Of those injuries, $11 \%(n=15)$ were
Issue Theme Surgeon Health; Guest Editor: Jennifer S. Davids, MD, FACS, FASCRS
Copyright (c) 2019 by Thieme Medical Publishers, Inc., 333 Seventh Avenue, New York, NY 10001, USA. Tel: +1(212) 584-4662.
DOI https://doi.org/ 10.1055/s-0039-1693010. ISSN 1531-0043. 
high-risk injuries (hepatitis B virus [HBV], hepatitis C virus $[\mathrm{HCV}]$, or human immunodeficiency virus [HIV]). Only three injuries were treated with postexposure prophylaxis. Fellows in the study had the highest number of sharps injuries $(4.3 \pm 2.9$ injuries per participant) and the highest rate of unreported injury ( $1.5 \pm 2.3$ injuries per participant). The most common reasons for self-injury were cited as "careless/ accidental" (52.2\%) and "rushed" (20.3\%). Injuries most commonly occurred between 07:30 and 18:00 hours. Of the sharps injuries, only $29 \%$ were injured by another individual rather than themselves.

Choi et $\mathrm{al}^{5}$ performed a similar survey-based study of sharps injuries at a single academic institution to determine the barriers to reporting and seeking treatment. The majority of respondents (55\%) had at least one sharps injury in the workplace. However, only $64 \%$ of those injuries were actually reported using proper channels. Medical students and residents were more likely to cite "fear" as a reason for not reporting sharps injuries. The majority (65\%) of respondents did not report exposure because either the process was "time-consuming" or the patient involved was perceived to be at low risk.

Focused initiatives to reduce sharps injuries are not always effective. A study from a single teaching hospital in Ireland looked at changes in sharps injuries between 1998 and 2000 and between 2008 and 2010. ${ }^{6}$ A European Union Directive on sharps was implemented between the two time periods. Elements in the directive included reducing unnecessary use of sharps, implementing safe procedures for disposing of sharps, banning the practice of recapping needles, and use of safety-engineered devices. Despite these initiatives, the authors found no significant change in the incidence of sharps injuries over the study period.

\section{Mucocutaneous Exposure}

Exposure to BBFs can also occur through mucocutaneous routes (i.e., splash, spray or spatter), failure of personal protective equipment, or inadequate hand hygiene. In the EXPO-S.T.O.P. (Exposure Survey of Trends in Occupational Practice) 2015 study, ${ }^{2}$ there were 2,735 reported mucocutaneous exposures, comprising $29 \%$ of BBF exposures reported. Bacteria and viruses can be transmitted through various body fluids, although they are dependent on the organism. For example, while HIV transmission from splash exposure is extremely low risk, hepatitis B can be transmitted without any visible blood and can remain virulent on environmental surfaces for up to 7 days.

A prospective study of the rates of splash exposure to the face was performed by a single surgeon performing a wide variety of cases over a 1 -year period. ${ }^{7}$ Eye protection and face masks were examined at the conclusion of operations for evidence of splash exposure. Of 384 operations, $45 \%$ had visible BBF present on the eye protection, whereas $24.2 \%$ had visible BBF on the mask. Vascular surgery and amputation procedures had the highest rates of splash. Surprisingly, up to $50 \%$ of laparoscopic procedures also had BBF splash on protective lenses and $17 \%$ on masks.

\section{Rates of Transmission}

\section{Hepatitis B}

HBV infection is a well-recognized occupational risk for surgeons. Blood contains the highest HBV titers of all body fluids and is the most important vehicle of transmission in the health care setting. Hepatitis B surface antigen ( $\mathrm{HBsAg}$ ) is also found in several other body fluids including breast milk, bile, cerebrospinal fluid, feces, nasopharyngeal washings, saliva, semen, sweat, and synovial fluid. The risk of HBV infection is primarily related to the degree of contact with blood and also to the hepatitis B e antigen (HBeAg) status of the source person. With needlestick injuries, the risk of developing clinical hepatitis if the blood is both HBsAg- and HBeAg-positive is 22 to $31 \%$, whereas the risk of developing serologic evidence of HBV infection is 37 to $62 \%$. By comparison, the risk of developing clinical hepatitis from a needle contaminated with HBsAg-positive, HBeAg-negative blood is 1 to $6 \%$, whereas the risk of developing serologic evidence of HBV infection is 23 to $37 \% .{ }^{8}$ Fortunately, vaccines and immune globulin are available for HBV, and thus the risk of seroconversion is low as long as proper vaccination or postexposure treatment is followed.

\section{Hepatitis C}

HCV is not transmitted efficiently through occupational exposures to blood and rarely occurs from mucous membrane exposures to blood. Risk of transmission after needlestick exposure to HCV has been estimated to be $1.8 \%$ (range: $0-10 \%$ ). Egro et $\mathrm{al}^{9}$ looked at the risk of transmission of HCV at a major academic medical center in the United States. They performed a longitudinal analysis of a prospectively maintained database from 2002 through 2015 at hospitals in their health system. Potential exposures included sharps and mucocutaneous exposures. During the study period, 1,361 cases of BBF exposure were identified, with $65 \%$ of cases caused by sharps injuries, $33.7 \%$ mucocutaneous, and $1.3 \%$ uncertain. Only $6.9 \%$ of the sources were coinfected with HIV and $3.7 \%$ were coinfected with HBV. The overall seroconversion rate in this study was $0.1 \%$ for $\mathrm{HCV}$. The two conversions occurred with sharps injuries with blood exposure involving hollow-bore needles. The two people who seroconverted were not exposed to patients with coinfection and thus were only exposed to HCV. Based on the rate of seroconversion from this study and previously published data, the authors calculated an overall seroconversion rate to $\mathrm{HCV}$ of $0.7 \%$ (range: $0-10 \%){ }^{9}$

\section{HIV}

The average risk of HIV transmission after percutaneous exposure to HIV-infected blood has been estimated to be approximately $0.3 \%{ }^{10}$ and that after a mucous membrane exposure has been estimated to be approximately $0.09 \%{ }^{11}$ The risk of transmission after exposure to fluids or tissues other than HIV-infected blood also has not been quantified but is probably considerably lower than that for blood exposures. A large prospective study evaluating BBF 
exposures between 2002 and 2015 analyzed the exposure risk, use of postexposure prophylaxis, and seroconversion for HIV. In this study, $52.6 \%$ were sharps injuries, whereas $43.2 \%$ were mucocutaneous exposures. Only $21.1 \%$ of exposed health care workers received postexposure prophylaxis. No exposed health care workers underwent seroconversion. The authors calculated a seroconversion rate from all BBF exposures of $0.13 \%$ (range: $0-1.5 \%)^{12}$

According to the Centers for Disease Control (CDC), ${ }^{13}$ the risk of becoming infected after a needlestick from an HIVinfected patient is $0.23 \%$. Cases of HIV that are acquired through occupational exposures are considered rare and should be reported to the state health department and CDC coordinator, as they are considered "cases of public health importance."

\section{Postexposure Treatment and Prophylaxis}

Treatment for exposures of potential BBF depends on the type of viral exposure (-Table 1). Prompt reporting of the event and proper testing of the source patient and exposed health care worker are strongly recommended.

\section{Hepatitis B}

Hepatitis B is most often transmitted through blood, as it contains the highest viral titers. HBV can also be transmitted to health care workers through cerebrospinal, synovial, pleural, peritoneal, pericardial and amniotic fluids, and can be transmitted without any visible blood. ${ }^{14}$ While HBsAg may be present in breast milk, bile, feces, nasopharyngeal washings, and sweat, they actually contain low quantities of infectious HBV. HBV can remain infectious on environmental surfaces for up to 7 days. Fortunately, the HBV vaccine is protective against acute and chronic infection in patients who are properly vaccinated and responsive to the vaccine.

Health care providers who have contact with patients or blood and are at an ongoing risk of percutaneous injuries should be tested every 1 to 2 months after completion of the three-dose vaccination series for antihepatitis B surface antibody (anti-HBS). ${ }^{14}$ If the health care worker is a documented nonresponder (anti-HBS $<10 \mathrm{mIU} / \mathrm{mL}$ ), the worker been incompletely vaccinated, or the response is unknown, then the source patient should be tested for the HBsAg. If HBsAg is positive in the patient, then documented nonresponders should receive two doses of hepatitis B immune globulin. In health care workers who are incompletely vaccinated against HBV or in whom response is unknown, one dose of the hepatitis immune globulin and a complete series of vaccines should be given. Baseline testing for HBV should be obtained immediately after exposure with followup in 6 months in those who are not immune at the time of exposure. Booster doses of hepatitis B vaccine are not necessary, and periodic serologic testing to monitor antibody concentrations after completion of the vaccine series is not recommended.

\section{Hepatitis C}

For hepatitis $\mathrm{C}$ exposure, the $\mathrm{CDC}$ does not recommend postexposure prophylaxis. ${ }^{13,15}$ The initial step is testing the source for HCV RNA. If the source is HCV RNA positive, then the health care worker should be tested within 48 hours for antihepatitis C antibody (anti-HCV). If this is negative, then the worker should be followed again with an HCV RNA test after 3 weeks. If the source was anti-HCV positive, then the exposed health care worker should undergo reflex HCV RNA testing. After that, if the HCV RNA test is positive either immediately or after 3 weeks of exposure, then treatment should be pursued under the care of a practitioner with expertise in the assessment of liver disease.

\section{HIV}

In general, postexposure prophylaxis with antiretroviral medications is recommended for all BBF exposure to HIV. ${ }^{13,16}$ Once an exposure has occurred, the HIV status of the source patient should be determined. There are rapid HIV tests that have been approved by the U.S. Food and Drug Administration, with

Table 1 Risk of transmission and exposure recommendations for viral exposures

\begin{tabular}{|c|c|c|c|c|}
\hline & \multicolumn{2}{|c|}{ Risk of transmission } & \multirow[t]{2}{*}{ Preexposure } & \multirow[t]{2}{*}{ Postexposure } \\
\hline & Splash & Needlestick & & \\
\hline Hepatitis B & $<1 \%$ & $\begin{array}{l}1.8 \% \\
(0.5-2.8)\end{array}$ & $\begin{array}{l}\text { HBV vaccine series } \\
\text { Confirm immunity } \\
\text { with anti-HBS levels }\end{array}$ & $\begin{array}{l}\text { No intervention if immune } \\
\text { Test source and administer HBIG and/or vaccine } \\
\text { series if not immune }\end{array}$ \\
\hline Hepatitis C & $<1 \%$ & $\begin{array}{l}1.8 \% \\
(0-7)\end{array}$ & - & $\begin{array}{l}\text { Test source for HCV RNA } \\
\text { If source positive, check anti-HCV levels within } 48 \text { h; } \\
\text { if positive, refer to a specialist } \\
\text { If negative, retest in } 3 \text { wk }\end{array}$ \\
\hline HIV & $\begin{array}{l}0.13 \% \\
(0-1.5)\end{array}$ & $\begin{array}{l}0.23 \% \\
(0-1.5)\end{array}$ & - & $\begin{array}{l}\text { Test source for HIV } \\
\text { Begin three-drug PEP } \\
\text { If source negative, stop PEP; if positive, continue PEP for } 4 \text { wk } \\
\text { Repeat testing of exposed up to } 6 \text { mo to assess } \\
\text { for seroconversion }\end{array}$ \\
\hline
\end{tabular}

Abbreviations: HBIG, hepatitis B immune globulin; HBS, hepatitis B surface antibody; HBV, hepatitis B virus; HCV, hepatitis C virus; HIV, human immunodeficiency virus; PEP, postexposure prophylaxis. 
results available within 30 minutes, although standard testing can also be administered. BBF exposure should be considered urgent and treated immediately. Postexposure prophylaxis should be started as soon as possible, ideally within hours. Postexposure HIV prophylaxis typically consists of at least a three-drug regimen for high-risk sources. ${ }^{16}$ This regimen may be tailored based on the type of HIV infection of the source and can be stopped if the test of the source patient is negative. According to the U.S. Public Health Service recommendations, the preferred postexposure HIV prophylaxis regimen consists of raltegravir $400 \mathrm{mg}$ twice daily, tenofovir $300 \mathrm{mg}$ daily, and emtricitabine $200 \mathrm{mg}$ once daily. ${ }^{16}$ The latter two medications are available as a combination medication. Once postexposure prophylaxis is initiated and if the source is confirmed HIV-positive, the exposed worker should continue treatment for 4 weeks. Follow-up counseling, testing, and medical evaluation should be performed after exposure with typical intervals of 6 weeks, 12 weeks, and 6 months to assess for seroconversion. Newer generation testing involving a combination of HIV p24 antigen and HIV antibody can detect seroconversion even earlier. If this type of testing is used, then HIV testing can be concluded after 4 months of exposure.

Postexposure prophylaxis does have its drawbacks, however, and these are mainly related to medication side effects. The most common side effects of postexposure prophylaxis medications are nausea and generally not feeling well. Additional side effects include headaches, fatigue, vomiting, and diarrhea. While on postexposure prophylaxis, health care workers should be followed for drug toxicity. Monitoring with complete blood count, renal, and hepatic panels should be performed at baseline and after 2 weeks of treatment. Lunding et $\mathrm{al}^{17}$ performed a retrospective review of health care workers with BBP exposures who underwent postexposure prophylaxis from 1999 to 2012 in Denmark. In this study, there were 411 exposed workers who were initiated on prophylaxis. Of the source patients, $67 \%$ were confirmed to be HIV-positive. Time to initiation of prophylaxis was 2.5 hours (range: $0.15-28.5$ ). Of the exposed health care workers taking postexposure prophylaxis, $50.9 \%$ had adverse effects, $22.1 \%$ had no adverse reactions, and $27 \%$ had missing data. Several combinations of drugs were used during the study period, and there was no significant difference in side effects among regimens. Frequency of adverse effects was higher when the source patient was confirmed to be HIV-positive (59.1 vs. $34.1 \% ; p<0.001$ ). However, only $6.6 \%$ of exposed health care workers stopped postexposure prophylaxis due to adverse effects. The majority (65.5\%) of exposed health care workers completed the regimen, and 19.6\% stopped it because the source patient was HIV-negative. The authors could not determine the number of days missed from work due to insufficient data. ${ }^{17}$

\section{Economic Cost of Blood or Body Fluid Exposure}

Exposure of BBF to health care workers involves large direct and indirect costs. Baseline and follow-up testing, health care visits, postexposure prophylaxis, medications for side effects, and worker's compensation comprise direct costs. Indirect costs also place a large burden on the health care system, including lost time and wages diverted to seeking medical attention, time used to treat an employee or test the source patient, and missed work. Mannocci et $\mathrm{al}^{18}$ performed a systematic review to determine the economic impact of sharps injuries in the literature. In total, 14 studies from Europe, America, Asia, and Australia were reviewed. Using the 2015 international U.S. dollar as a unit, the authors calculated an overall aggregate cost (direct + indirect) of $\$ 650$ to $\$ 750$, with a median of $\$ 747$. The actual costs of treating infections and intangible costs could not be calculated. With estimates of $385,000 \mathrm{BBF}$ exposures per year, the expenditure per year for the United States may be approximately $\$ 250,000,000$ to $\$ 300,000,000 .^{18}$

\section{Prevention of Blood or Body Fluid Exposure}

\section{Single versus Double Gloving}

Several studies have looked at the benefit of double gloves over single gloves in the operating room setting. In 2006, Tanner and Parkinson ${ }^{19}$ performed a Cochrane review of double gloving to prevent cross-infection between patient and health care worker. The study identified all randomized controlled trials investigating single versus double gloving. The primary outcome measured was rate of surgical site infections, and secondary outcomes were rates of perforations in the innermost surgical gloves and rates of blood-borne infections in postoperative patients or members of the surgical team. Overall, 31 trials were identified. Most of the studies did not include data on the primary or secondary outcomes of interest or were underpowered to draw conclusions in these areas. The authors concluded that a second pair of gloves protects the inner pair without affecting surgical performance. They also found that a glove liner between two pair of gloves reduces breaks to the inner glove, and extrathick gloves are as effective as wearing two pairs of gloves to reduce glove perforation.

In 2014, Mischke et $\mathrm{l}^{20}$ performed a Cochrane review of the use of single or double gloves in preventing cutaneous exposure injuries in health care personnel. The primary outcome of interest was exposure of health care workers to potentially contaminated bodily fluids through either sharps injury, needlestick, blood stains on the skin, or glove perforations. Surgeon dexterity was the secondary outcome. In total, 34 articles were included, and participants in all studies were surgeons. The authors found that there is moderate quality evidence that double gloving reduces risk of glove perforation ( 0.29 ; $95 \%$ confidence interval: $0.23-0.37)$ and the risk of blood stains on the skin $(0.35 ; 95 \%$ confidence interval: $0.17-0.70){ }^{20}$ The authors also concluded that there is moderate- to lowquality evidence that use of a glove indicator system reduces the total number of glove perforations but reduces number of glove perforations per glove used. Double gloving did not correlate with loss of surgeon dexterity. Overall, the authors concluded that double gloving compared with single gloving reduces perforations and blood stains on the skin, which can decrease BBF exposures and reduce the risk of contracting a serious viral infection. 


\section{Eye Protection}

Use of face shields or protective eyewear can help prevent accidental splash exposure of acutely expelled bodily fluids to the skin and eyes. Eye protection should be considered when there is a risk of splash from blood, body fluids, secretions, or excretions. There is surprisingly little research regarding the efficacy of face shields or eyewear and no universal standard for eye protection. ${ }^{20}$ Splash to protective glasses may occur in up to $25 \%$ of operations in general surgery. ${ }^{21,22}$ Mansour et al ${ }^{23}$ found a $30 \%$ contamination rate of combined use of surgical mask with integral eye shields in orthopaedic surgeries, whereas Loveridge et $\mathrm{al}^{24}$ noted a $40 \%$ rate of contamination of a combined surgical mask with visors. OSHA recommends that masks with eye protection devices, including goggles or glasses with solid side shields or chin-length face shields, should be worn where there is a risk of splash, spray, or spatter of bodily fluids, and contamination with potentially infectious materials. ${ }^{25}$

\section{Additional Recommendations for Surgeons}

The American College of Surgeons (ACS) has published a statement on sharps safety with recommendations for best practices (-Table 2). ${ }^{26}$ To reduce BBF exposures, the ACS recommends universal adoption of double gloving with the caveat that single gloving could be used if double gloving were to compromise the safety of the operation or of the patient. The ACS also recommends the use of blunt-tip suture needles to close fascia and muscle, as these have been shown to reduce the rate of glove puncture from $38 \%$ to $6 \%$, as well as the use of a "hands-free technique" for handling sharp instruments. ${ }^{26}$ The latter involves having the surgeon place sharps in a neutral zone such as a towel, Mayo stand, basin, or magnetic pad rather than handing it directly to another person. Data supporting this technique are inconclusive, but it has also been recommended by the OSHA and the Association of Perioperative Registered Nurses.

\section{Recommendations for Endoscopists}

During colonoscopy, the major risk of BBF exposure is from feces/colonic effluent. There are currently no specific personal protective equipment guidelines for endoscopists. In general, compliance with OSHA and CDC standards and with individual institution policies should be followed. Studies have shown a splash rate of $9.5 \%$ to the skin of the face for endoscopists, with up to $4.1 \%$ splash to the eyes. ${ }^{27}$ Gowns are recommended to protect the skin and clothing from contamination. Hand hygiene should be performed immediately after removing personal protective equipment, as there may

Table 2 Recommendations for the prevention of blood and bodily fluid exposure

\begin{tabular}{|l|l|}
\hline Operating room & Endoscopy suite \\
\hline Double gloving & Eye protection \\
Face mask & Face mask \\
Neutral zone passage of sharps & Full gown \\
in high-risk patients & \\
\hline
\end{tabular}

be unseen leaks or glove perforations. Eyes can be exposed through splash or spatter or by touching the eye with contaminated fingers, leading to conjunctivitis or systemic infection. ${ }^{27,28}$ Eye protection should be comfortable, allow sufficient peripheral vision, and must be adjustable. Personal eyeglasses and contact lenses are not considered adequate.

\section{Other Sources of Exposure}

\section{Smoke Exposure}

In the operating room, surgeons are exposed to smoke inhalation in procedures where cautery or vessel-sealing energy devices are used. Studies have shown that operating room smoke is potentially hazardous and as mutagenic as cigarette smoke. ${ }^{29-32}$ In addition to the hazards of smoke inhalation from particles, viable cells and infectious viral genes/viruses have been identified in surgical smoke plumes, although this is a rare occurrence. ${ }^{33-35}$ Burning 1 gram of tissue releases the same level of mutagenic toxins as smoking three to six cigarettes. ${ }^{31}$ The standard surgical mask or surgical laser masks do not seal to the face and do not filter particles smaller than 1 micrometer $(\mathrm{mcm})$ in size. ${ }^{36}$ Typical procedures using electrocautery can generate particles $0.07 \mathrm{mcm}$ in size, whereas lasers generate particles $0.31 \mathrm{mcm}$ in size and ultrasonic devices generate particles $0.35 \mathrm{mcm}$ in size. Small inhaled particles $0.5 \mathrm{mcm}$ in size can cause acute and chronic respiratory changes. Bacteria and viral cells have been detected in surgical smoke up to 72 hours later. ${ }^{31}$ With fulguration of anal condyloma, N95 respirators are highly recommended because of the risk of dispersed human papillomavirus in the surrounding air. ${ }^{37}$ An N95 respirator is a respiratory protective device designed to achieve a very close facial fit and very efficient filtration of airborne particles, exceeding that of a loosely fitted face mask, and blocking at least $95 \%$ of very small $(0.3 \mathrm{mcm})$ test particles. Many operating rooms are also making efforts to use smoke evacuation devices when using electrocautery for open and laparoscopic procedures, although the true impact on the reduction of bacterial and viral particles in the operating room and possible infection are currently unknown.

\section{Clostridium Difficile Exposure}

Clostridium difficile (CD) is one of the most common nosocomial infections and the leading cause of nosocomial diarrhea. Colorectal surgeons are increasingly involved in the care of patients with CD infection. As community-acquired infections increase, exposure of colorectal surgeons to patients with $\mathrm{CD}$ infection in clinics and during endoscopy may rise as well. Of importance, $\mathrm{CD}$ spores are excreted in feces and can be present in multiple skin sites in affected patients.

Studies have shown that health care workers' hands can be contaminated with vegetative forms and spores of $\mathrm{CD}$ after caring for patients. ${ }^{38} \mathrm{~A}$ prospective study at a large university hospital in France analyzed risk factors for CD contamination, comparing hand contamination rates between health care workers caring for $\mathrm{CD}$ patients and unexposed workers. ${ }^{39}$ They found that $24 \%$ of health care workers' hands had CD spores compared with $0 \%$ in the unexposed group $(p<0.001)$, 
despite standard hand hygiene practices. The most significant risk factors for $\mathrm{CD}$ spore contamination of hands were highrisk contact activities, which are defined as patient washing, diaper change, bed linen change, handling of bedpan, digital rectal examination, colonoscopy, administering enema, and cleansing of the perineal area, as well as lack of gloves. These contamination rates were in the setting of standard enteric precaution recommendations including wearing disposable gowns with full-length sleeves, gloves, hand hygiene with alcohol-based solution before gloving, and soap and water washing after glove removal. This study also showed that hand contamination was more common among nursing assistants (42\%); however, $19 \%$ of nurses and $23 \%$ of physicians also had hand contamination with CD spores. ${ }^{39}$ Those with CD spores were also more likely to be exposed to a higher number of contacts with a longer duration of high-risk contact activities. Despite high rates of spore contamination of health care providers, no data are available on the actual incidence of CD disease (diarrhea or colitis) in this population.

As colorectal surgeons frequently perform lower gastrointestinal assessment and procedures in multiple settings, with the inherent exposure and contamination risk, careful attention to best practices for hand hygiene is recommended. Special attention should be paid to cleaning of surfaces that infected patients may touch when visiting endoscopy or clinical settings.

Although current measures to prevent CD infection are effective, they have significant limitations. Future methods of prevention may need to focus on extending cleaning and disinfection procedures beyond the immediate surroundings of symptomatic carriers. Potential targets to prevent acquisition of $\mathrm{CD}$ in the community include household settings, long-term care facilities, and outpatient settings. The role of livestock in entertaining transmission, screening for asymptomatic $\mathrm{CD}$ carriage, microbiota-sparing agents, and vaccines requires further investigation.

\section{Radiation Exposure}

Colorectal surgeons may be exposed to radiation during certain procedures such as defecography and interventional procedures (i.e., colonic stent placement, sacral neuromodulation, endoscopic dilatation). The primary source of radiation is from radiation scattered from the patient. Surgeons can limit their exposure to radiation by limiting the time of application or radiation to patients. The lowest possible radiation dose should be used. Appropriate shielding should be used, and staff can increase the distance away from the radiation beam. Radiation exposure from a point source decreases by the inverse square of distance from the source. More than $90 \%$ of scattered radiation can be blocked by using lead aprons. Using lightweight two-piece aprons transfers half of the weight to the user's hips, decreasing strain on the wearer's shoulders and back. For surgeons performing frequent procedures, radiation exposure dosimeters should be worn outside of the lead shielding at the collar level. ${ }^{40}$ For health care workers who are pregnant, the total dose to the fetus should be limited to 500 millirems over the entire gestation. ${ }^{41}$

\section{Summary and Conclusions}

Workplace exposures in colorectal surgery are common, with a variety of unique exposure risks at different health care settings including clinics, hospital wards, endoscopy settings, and the operating rooms. Colorectal surgeons can be exposed through both inadvertent sharps injuries and undetected glove punctures or tears during both open and minimally invasive procedures. In the operating room, double gloving is highly recommended unless the use of double gloves was to increase risk to the patient. Eye protection is also highly recommended, as there is a significant risk of splash or splatter from BBFs, particularly during colorectal procedures. Even if endoscopy or minor anorectal cases are performed in the operating room, proper personal protective equipment should be worn and prompt and adequate hand hygiene should be performed.

If a BBF exposure is experienced, proper channels for reporting and testing should be followed. For potential HIV exposure, initiation of postexposure prophylaxis should not be delayed. Following such protocols not only helps protect the surgeon's health but also helps determine incidence and interventions that may impact future BBF exposures. Special attention should be paid to hand hygiene and proper cleaning of potentially contaminated surfaces when treating patients with $\mathrm{CD}$ infection, as even when wearing gloves, hands can become contaminated with spores. Following best practices for the prevention of BBF exposures also sets a good example for trainees and team members, which further helps promote a culture of safety.

Conflict of Interest

None declared.

\section{References}

1 Panlilio AL, Orelien JG, Srivastava PU, Jagger J, Cohn RD, Cardo DM; NaSH Surveillance Group; EPINet Data Sharing Network. Estimate of the annual number of percutaneous injuries among hospitalbased healthcare workers in the United States, 1997-1998. Infect Control Hosp Epidemiol 2004;25(07):556-562

2 Grimmond T, Good L. Exposure Survey of Trends in Occupational Practice (EXPO-S.T.O.P.) 2015: a national survey of sharps injuries and mucocutaneous blood exposures among health care workers in US hospitals. Am J Infect Control 2017;45(11): 1218-1223

3 Myers DJ, Lipscomb HJ, Epling C, et al. Surgical procedure characteristics and risk of sharps-related blood and body fluid exposure. Infect Control Hosp Epidemiol 2016;37(01):80-87

4 Hasak JM, Novak CB, Patterson JMM, Mackinnon SE. Prevalence of needlestick injuries, attitude changes, and prevention practices over 12 years in an urban academic hospital surgery department. Ann Surg 2018;267(02):291-296

5 Choi LY, Torres R, Syed S, et al. Sharps and needlestick injuries among medical students, surgical residents, faculty, and operating room staff at a single academic institution. J Surg Educ 2017; 74(01):131-136

6 Kevitt F, Hayes B. Sharps injuries in a teaching hospital: changes over a decade. Occup Med (Lond) 2015;65(02):135-138

7 Davies CG, Khan MN, Ghauri ASK, Ranaboldo CJ. Blood and body fluid splashes during surgery-the need for eye protection and masks. Ann R Coll Surg Engl 2007;89(08):770-772 
8 Werner BG, Grady GF. Accidental hepatitis-B-surface-antigenpositive inoculations. Use of e antigen to estimate infectivity. Ann Intern Med 1982;97(03):367-369

9 Egro FM, Nwaiwu CA, Smith S, Harper JD, Spiess AM. Seroconversion rates among health care workers exposed to hepatitis $C$ viruscontaminated body fluids: the University of Pittsburgh 13-year experience. Am J Infect Control 2017;45(09):1001-1005

10 Bell DM. Occupational risk of human immunodeficiency virus infection in healthcare workers: an overview. Am J Med 1997;102 (5B):9-15

11 Ippolito G, Puro V, De Carli G. The risk of occupational human immunodeficiency virus infection in health care workers. Italian Multicenter Study. The Italian Study Group on Occupational Risk of HIV infection. Arch Intern Med 1993;153(12):1451-1458

12 Nwaiwu CA, Egro FM, Smith S, Harper JD, Spiess AM. Seroconversion rate among health care workers exposed to HIV-contaminated body fluids: the University of Pittsburgh 13-year experience. Am J Infect Control 2017;45(08):896-900 U.S.

13 U.S. Public Health Service. Updated U.S. Public Health Service guidelines for the management of occupational exposures to HBV, $\mathrm{HCV}$, and HIV and recommendations for postexposure prophylaxis. MMWR Recomm Rep 2001;50(RR-11):1-52

14 Centers for Disease Control and Prevention. CDC guidance foe evaluating health-care personnel for hepatitis B protection and for administering postexposure management. MMWR Recomm Rep 2013;62:1-19

15 Centers for Disease Control. Information for healthcare personnel potentially exposed to Hepatitis C virus (HCV). Available at https://www.cdc.gov/hepatitis/pdfs/testing-followup-exposedhc-personnel.pdf. Accessed January 30, 2018

16 Kuhar DT, Henderson DK, Struble KA, et al; US Public Health Service Working Group. Updated US Public Health Service guidelines for the management of occupational exposures to human immunodeficiency virus and recommendations for postexposure prophylaxis. Infect Control Hosp Epidemiol 2013;34(09):875-892

17 Lunding S, Katzenstein TL, Kronborg G, et al. The Danish PEP Registry: experience with the use of post-exposure prophylaxis following blood exposure to HIV from 1999-2012. Infect Dis (Lond) 2016;48(03):195-200

18 Mannocci A, De Carli G, Di Bari V, et al. How much do needlestick injuries cost? A systematic review of the economic evaluations of needlestick and sharps injuries among healthcare personnel. Infect Control Hosp Epidemiol 2016;37(06):635-646

19 Tanner J, Parkinson H. Double gloving to reduce surgical crossinfection. Cochrane Database Syst Rev 2006;(03):CD003087

20 Mischke C, Verbeek JH, Saarto A, Lavoie MC, Pahwa M, Ijaz S. Gloves, extra gloves or special types of gloves for preventing percutaneous exposure injuries in healthcare personnel. Cochrane Database Syst Rev 2014;(03):CD009573

21 Brearley S, Buist LJ. Blood splashes: an underestimated hazard to surgeons. BMJ 1989;299(6711):1315

22 Roberge RJ. Face shields for infection control: a review. J Occup Environ Hyg 2016;13(04):235-242

23 Mansour AA III, Even JL, Phillips S, Halpern JL. Eye protection in orthopaedic surgery. An in vitro study of various forms of eye protection and their effectiveness. J Bone Joint Surg Am 2009;91 (05):1050-1054
24 Loveridge JM, Gozzard C, Bannister GC. The effectiveness of a visor as a surgical barrier: an inverted position is better. J Hosp Infect 2006;62(02):251-253

25 Occupational Safety and Health Administration (OSHA). Bloodborne Pathogens standard. Available at https://www.osha.gov/pls/oshaweb/owadisp.show_document?p_table $=$ STANDARDS\&p_id $=100$ 51">https://www.osha.gov/pls/oshaweb/owadisp.show_document? p_table=STANDARDS\&p_id=10051. Accessed January 31, 2018

26 American College of Surgeons (ACS) Committee on Perioperative Care. Revised statement on sharps safety. Bull Am Coll Surg 2016; 101(10):53-55

27 Mohandas KM, Gopalakrishnan G. Mucocutaneous exposure to body fluids during digestive endoscopy: the need for universal precautions. Indian J Gastroenterol 1999;18(03):109-111

28 Benter T, Klühs L, Teichgräber UK, Riechert F, Ludwig WD, Dörken B. Need for safety goggles for endoscopy. Endoscopy 2003;35(09):803

29 Tomita Y, Mihashi S, Nagata K, et al. Mutagenicity of smoke condensates induced by CO2-laser irradiation and electrocauterization. Mutat Res 1981;89(02):145-149

30 U.S. Department of Health and Human Services, National Institute for Occupational Safety and Health. Health Hazard Evaluation Report. HETA 85-126-1932, 1988. Available at https://www.cdc. gov/niosh/hhe/reports/pdfs/85-126-1932.pdf. Accessed on February 12,2018

31 Brüske-Hohlfeld I, Preissler G, Jauch KW, et al. Surgical smoke and ultrafine particles. J Occup Med Toxicol 2008;3:31

32 Champault G, Taffinder N, Ziol M, Riskalla H, Catheline JM. Cells are present in the smoke created during laparoscopic surgery. $\mathrm{Br} \mathrm{J}$ Surg 1997;84(07):993-995

33 Baggish MS, Poiesz BJ, Joret D, Williamson P, Refai A. Presence of human immunodeficiency virus DNA in laser smoke. Lasers Surg Med 1991;11(03):197-203

34 Ferenczy A, Bergeron C, Richart RM. Human papillomavirus DNA in $\mathrm{CO} 2$ laser-generated plume of smoke and its consequences to the surgeon. Obstet Gynecol 1990;75(01):114-118

35 Ziegler BL, Thomas CA, Meier T, Müller R, Fliedner TM, Weber L. Generation of infectious retrovirus aerosol through medical laser irradiation. Lasers Surg Med 1998;22(01):37-41

36 Lewin JM, Brauer JA, Ostad A. Surgical smoke and the dermatologist. J Am Acad Dermatol 2011;65(03):636-641

37 Ferenczy A, Bergeron C, Richart RM. Carbon dioxide laser energy disperses human papillomavirus deoxyribonucleic acid onto treatment fields. Am J Obstet Gynecol 1990;163(4 Pt 1):1271-1274

38 McFarland LV, Mulligan ME, Kwok RY, Stamm WE. Nosocomial acquisition of Clostridium difficile infection. N Engl J Med 1989; 320(04):204-210

39 Landelle C, Verachten M, Legrand P, Girou E, Barbut F, Brun-Buisson C. Contamination of healthcare workers' hands with Clostridium difficile spores after caring for patients with $C$. difficile infection. Infect Control Hosp Epidemiol 2014;35(01):10-15

40 Amis ES Jr, Butler PF, Applegate KE, et al; American College of Radiology. American College of Radiology white paper on radiation dose in medicine. J Am Coll Radiol 2007;4(05):272-284

41 Pedrosa MC, Farraye FA, Shergill AK, et al; ASGE Technology Committee. Minimizing occupational hazards in endoscopy: personal protective equipment, radiation safety, and ergonomics. Gastrointest Endosc 2010;72(02):227-235 